IDEAs IN EcRlogy AND EVRLutian 6: 1-4, 2013

doi:10.4033/iee.2013.6.1.c

(C) 2013 The Author. (C) Ideas in Ecology and Evolution 2013

Received 25 November 2012; Accepted 21 March 2013

Commentary

\title{
Dogmatic is problematic: Interpreting evidence for latitudinal gradients in herbivory and defense.
}

\author{
Angela T. Moles \\ Angela T. Moles (a.moles@unsw.edu.au), Evolution and Ecology Research Centre, School of Biological, Earth and \\ Environmental Sciences, The University of New South Wales, NSW 2052, Australia
}

\begin{abstract}
It has long been believed that plant-animal interactions, including herbivory, are more intense toward the tropics. The more intense interactions in the tropics are thought to have selected for higher levels of defenses against herbivores. These ideas are fundamental to our understanding of global patterns in diversity, and for our understanding of plant-animal interactions. However, recent analyses have tended not to support the traditional hypothesis of higher herbivory and defenses at lower latitudes. Despite mounting empirical evidence, many ecologists have been slow to re-assess their beliefs. I show clear evidence for citation bias, with papers that support the traditional idea being cited over six times as often as papers that show higher herbivory at higher latitudes and over four times as often as papers showing higher defense at higher latitudes. I also highlight examples where interpretations that are counter to the available empirical evidence have been published in high profile journals. I suggest that providing rigorous empirical tests for ideas that have become widely established without appropriate testing should be a priority for ecologists. We need to make sure the objectivity of peer-reviewed science stands out from the mass of unchecked opinion available on the web.
\end{abstract}

Key words: herbivory, chemical defense, latitude, citation bias, reification

Herbivory and plant defenses have enormous fitness consequences for both the plant and the animal populations involved (affecting plant ecological strategy, community structure, and biodiversity). Traditional theory suggested that interactions between species (including herbivory) would be more intense in the tropics, because herbivore populations are not knocked back by harsh winters, and because plants and animals in low latitude ecosystems have had longer to coevolve than have species in areas that experience glaciation (Schemske et al. 2009). The higher level of herbivory in low-latitude ecosystems is generally thought to have selected for higher levels of defense against herbivores (Coley and Aide 1991). These theories were very widely believed. However, recent syntheses of empirical data have not supported the idea that either herbivory, or plant defenses against herbivores are higher at lower latitudes (Moles et al. 2011, Poore et al. 2012). Unfortunately, it is our nature as humans to have trouble letting go of long-held theories, even when these are not well supported by empirical data. In this paper, I argue that belief has been shading our interpretation of the evidence regarding the latitudinal gradient in herbivory and defense.

I began by asking whether there was evidence for citation bias in studies of herbivory and chemical defense. I compiled data on citation rates for all of the papers that met the criteria for inclusion in Moles et al.'s (2011) meta-analyses. I did not complement these results with more recently published papers, to avoid problems with estimating citation rates for papers that have been available for citing for a very short time. To account for the differences in the length of time that different papers have been available for citing, I used citations per year as the response variable. Papers were grouped in to those showing a significant $(\mathrm{P}<0.05)$ result in the expected direction (or the expected result 

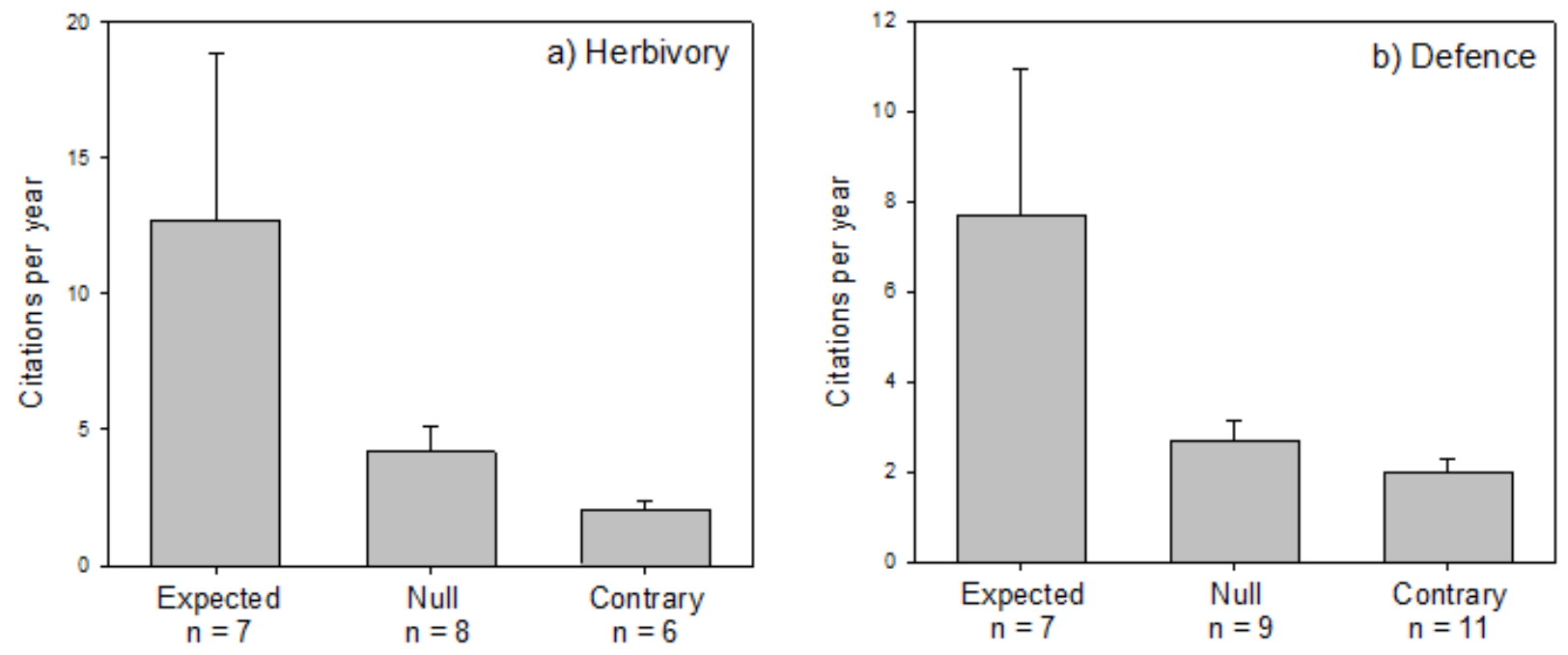

Figure 1. The number of citations per year (data collected from Google Scholar on 16 March 2013) for each of the studies of latitudinal gradients in a) herbivory in natural environments and b) chemical defenses against herbivores included in Moles et al. (2011). Sample sizes on the x axis are the number of studies in each category. Bars represent means, and error bars are one standard error. The "expected" result is higher herbivory or defense at lower latitudes.

and a null result), papers showing null or mixed results (mixed $=$ showing both significant expected and contrary results), and papers showing significant results in the contrary direction (or the contrary result and a null result). Because the data were not normally distributed, and the variance differed substantially between groups, I $\log _{10}$ transformed the data before applying ANOVA complemented by posthoc Tukey tests, and also used non-parametric Kruskal-Wallis tests to assess differences between groups.

Papers that show the expected higher herbivory at lower latitudes have been cited more than six times as often as have papers that show contrary results (Figure 1a). The differences in citation rate between studies with expected results and those with contrary results were significant in both parametric $(P=0.04)$ and nonparametric $(P=0.03)$ analyses. Similarly, papers that show the expected higher levels of chemical defense at lower latitudes have been cited over four times as often as have papers that show contrary results (Figure 1b), and these differences are significant in both parametric $(P=0.045)$ and non-parametric $(P=0.041)$ analyses. That is, there is evidence for substantial citation bias with respect to latitudinal gradients in both herbivory and defense.

There are not enough data to formally investigate the sources of variation in citation levels. However, there were two cases where the same lead author had published studies of herbivory with different results, and in both of these cases, the studies showing the expected result were more highly cited than were the studies showing null or contradictory results. The paper led by
Jonathan Adams that showed the expected result had been cited 4.6 times per year, while the highest citation rate among the four Adams papers with null or contrary results was 3.4 citations per year. Likewise, papers led by Steven Pennings showing the expected results have been cited 6.2 and 9.1 times per year, while the Pennings paper showing a null result had only been cited 2.7 times per year. There were also two cases where contrasting results for chemical defense had been published in the same journal. In Biochemical Systematics and Ecology, papers showing the expected result had been cited 2.3 and 1.1 times per year, a paper with mixed results had been cited 3.7 times per year, a null 0.4 times per year and a paper showing a contrary result had been cited 0.5 times per year. In the Journal of Chemical Ecology, a paper showing the expected result had been cited 23 times per year, while a null result was cited just 2.7 times per year. That is, the tendency for papers showing expected results to be more highly cited seems to hold true even for papers with the same author, or published in the same journal.

It seems that some bias in interpretation of latitudinal gradients in herbivory is also slipping through the peer review system. For instance, Salazar and Marquis (2012) recently published a paper in PNAS entitled "Herbivore pressure increases toward the equator". Their concluding paragraph began "Overall, we found support for the hypothesis that plants suffer greater herbivore pressure at lower latitudes". However, the relationship between herbivory and latitude was not significant for either of their study species $(P=0.85$ and $\mathrm{P}=0.23)$. The authors argued that because herbivore 
diversity and density was higher in the tropics, there is likely to be higher herbivore pressure at lower latitudes. Different types of herbivory might well have different effects on plants. However, Salazar and Marquis do not present any evidence that the greater diversity of herbivores at lower latitudes results in herbivore pressure (either as defined in Salazar and Marquis "the strength of natural selection imposed by herbivores for plant phenotypes that have greater fitness in the presence of those herbivores" or in its longstanding and common use as a synonym for herbivore damage). While they are quite clear about their results in their (otherwise excellent) paper, including acknowledging a "lack of significant differences in quantitative herbivore pressure across latitudinal sites", the phrasing of the title and overall conclusion are distinctly misleading.

My second example of claims that do not seem to match the evidence is from Schemske et al.'s (2009) review of latitudinal gradients in biotic interactions. These authors claimed that the latitudinal gradient in herbivory was one of the "best-supported examples" of a latitudinal gradient in biotic interactions. However, Schemske et al. (2009) cited just three papers on herbivory in their Annual Review of Ecology, Evolution and Systematics paper, all from the same lab, and all reporting higher herbivory toward the tropics. It is true that one of the papers they cited was a meta-analysis that compared rates of herbivory measured in 13 tropical and 19 temperate studies (Dyer and Coley 2002), and the other two were data compilations (Coley and Aide 1991, Coley and Barone 1996). All of these papers are excellent. However, at the time, there were at least 14 papers that presented primary data on the latitudinal gradient in herbivory, and only five of these showed the predicted negative relationship between latitude and herbivory (Moles et al. 2011). The failure to mention any studies that contradicted their hypothesis when such studies were in the majority suggests either a poorly done literature review, or a biased presentation of the available evidence.

We do not yet have conclusive evidence as to whether there is greater herbivory toward the tropics. Some of the most beautiful empirical studies have found higher herbivory at lower latitudes (e.g. Pennings et al. 2009), but recent meta-analyses that synthesise all the available data have not supported this hypothesis (Moles et al. 2011, Poore et al. 2012). We also have a great deal more work to do before we will understand global patterns in plant defense. Gathering quality evidence to address these questions is an important goal.

Cases where an idea has become widely accepted without appropriate testing are not uncommon in ecology (Slobodkin 2001). Much of our theory comes from the 1960s and 1970s, when advanced statistical analyses and huge datasets were simply not available. Identifying and testing these reified ideas is good for everybody. A scientist who provides the first broad empirical support for a widely believed hypothesis is likely to be very highly cited. Cases where the traditional ideas are not supported by data are likely to be even more important in clearing out false beliefs and opening space for the development of a new generation of ideas. In the meantime, we must judge theories on the basis of the available evidence, and it is our duty as reviewers to make sure that others do the same. In the current climate of hyper-availability of information, scientists must make it clear that published papers are more than just opinions, but rather the results of carefully designed research, checked by a rigorous peerreview system. After all, ecology is a science, not a faith, and if we want to be taken seriously by the public, we must defend our reputation as a source of unbiased information.

\section{Acknowledgements}

ATM was supported by a QEII fellowship from the Australian Research Council. Thanks to Habacuc Flores and Stephen Bonser for comments on the manuscript.

\section{Referees}

Jonathan Adams - jonadams@ andromeda.rutgers.edu Rutgers, The State University of New Jersey

Julia Koricheva - Julia.koricheva@rhul.ac.uk

Royal Holloway, University of London

\section{References}

Coley, P.D. and T.M. Aide. 1991. Comparison of herbivory and plant defenses in temperate and tropical broad-leaved forests. Pages 25-49 in Price, P.W. Lewinsohn, T.M., Fernandes, G.W., and W.W. Benson, editors. Plant-animal interactions: Evolutionary ecology in tropical and temperate regions. Wiley.

Coley, P.D. and J.A. Barone. 1996. Herbivory and plant defenses in tropical forests. Annual Review of Ecology and Systematics 27:305-335. CrossRef

Dyer, L.A. and P.D. Coley. 2002. Tritrophic interactions in tropical vs temperate communities. Pages 67-88 in Tscharntke, T. and B. Hawkins, editors. Multitrophic Level Interactions. Cambridge University Press. $\underline{\text { CrossRef }}$

Moles, A.T., Bonser, S.P., Poore, A.G.B., Wallis, I.R., and W.J. Foley. 2011. Assessing the evidence for latitudinal gradients in plant defence and herbivory. Functional Ecology 25: 380-388. CrossRef

Pennings, S.C., Ho, C-K, Salgado, C.S., Więski, K, Davé, N., Kunza, A.E, et al. 2009. Latitudinal 
variation in herbivore pressure in Atlantic Coast salt marshes. Ecology 90: 183-195. CrossRef

Poore, A.G.B., Campbell, A.H., Coleman, R.A., Edgar, G.J., Jormalainen, V., Reynolds, P.L., et al. 2012. Global patterns in the impact of marine herbivores on benthic primary producers. Ecology Letters 15: 912-922. CrossRef

Salazar, D. and R.J. Marquis. 2012. Herbivore pressure increases toward the equator. Proceedings of the National Academy of Sciences of the United States of America 109: 12616-12620. CrossRef

Schemske, D.W., Mittelbach, G.G., Cornell, H.V., Sobel, J.M., and K. Roy. 2009. Is there a latitudinal gradient in the importance of biotic interactions? Annual Review of Ecology, Evolution and Systematics 40: 245-269. CrossRef

Slobodkin, L.B. 2001. The good, the bad and the reified. Evolutionary Ecology Research 3: 1-13. 